\title{
Techno-Economic Design of a Stand-Alone Photovoltaic System for a Rural Community in the Ecuadorian Amazon
}

\author{
Cristhian A. Apolo Apolo ${ }^{1}$, Luis I. Minchala-Avila ${ }^{2}$, Pedro J. Franco Marques ${ }^{1}$ \\ ${ }^{1}$ Instituto Politécnico de Leiria, School of Technology and Management \\ ${ }^{2}$ Universidad de Cuenca, Department of Electrical, Electronic and Telecommunications Engineering
}

*Corresponding Author: Luis I. Minchala-Avila, Universidad de Cuenca, Department of Electrical, Electronic and Telecommunications Engineering, Ecuador.

\begin{abstract}
Providing universal access to electricity is a worldwide priority. Renewable Energy Sources (RES) play an important role in the supply of energy to remote areas, where grid electricity is not feasible or the cost of the grid extension is large. Photovoltaic Home Systems (PVHS) are typically used to provide electricity to the dwellings in off-grid rural communities. However, Centralized Photovoltaic Systems(CPVS) with their own Distribution Network (DN) is also being considered as an alternative for rural electrification. This paper analyzes these two options of electrical supply to provide energy to the rural community Yuwints in the Amazon region of Ecuador. The most suitable system is selected after a comparison of the Net Present Cost (NPC) of various renewable systems, e.g.PV-battery systems, Wind-battery systems, PV-Wind-battery systems, etc. The techno-economic analysis is carried out through the microgrid optimization Homer Energy software. The result of the present study proposes the CPVS as the best option to provide electrical supply for the community, allowing a full coverage of the load and guaranteeing a secure operation of the system.
\end{abstract}

Keywords: Solar home system, renewable energy sources, centralized photovoltaic system.

\section{INTRODUCTION}

Access to electricity is one of the main aspects in economic and social development. It is essential for a clean water provision, efficient lighting, heating, cooking, sanitation and healthcare, among others basic services. According to the International Energy Agency(IEA) about 16\% of the worldwide population does not have access to electricity or their energy requirements are covered by fossil fuels, and more than $38 \%$ of the population relies on the traditional biomass for cooking. Factors such as low population density, long distances between generation systems to consumers and difficult access hinder the power supply to a large part of the population, especially on rural and marginal urban areas.

In Ecuador especially in rural areas, the total percentage of households without electric energy is $10,97 \%$. The localities belonging to the Amazon region are the ones with the lowest electrical coverage. Isolated communities in the Amazon region are characterized to be very far away from each other, to be composed of scattering housing, having very low population density and to be surrounded by dense vegetation. Reaching these communities is typically done through small paths, fluvial access and reduced few cases by small planes. Therefore, implementing transmission and distribution lines for supplying energy is costly and harmful to the environment. Hence, the use of RES represents a brilliant opportunity for power generation purposes.

Many contributions related with the design of RES systems for rural areas by using Homer Energy are presented in[1][2][3]. Nevertheless there are few studies that compare solar PVHS and CPVS for rural electrification. For instance, reference[4] describes a CPVS approach as the best option for a particular off-grid application, but it requires extended planning and high initial investments, whereas the PVHS approach can be gradually built bottom-up. Reference [5] studies the economic viability of the implementation of a CPVS in villages with a large number of dwellings, densely populated and

\footnotetext{
${ }^{1}$ This data was obtained from the Ministry of Electricity and Renewable Energy. [online]. Available: http://www.energia.gob.ec/electrificacion-rural-con-energias-renovables/
} 
located on flat terrains. It is concluded that the most convenient option for small villages situated in rough terrains with scattered dwellings is PVHS.

This paper presents a detailed analysis of two options of electrical supply to provide electricity to the rural community Yuwints in the Amazon region of Ecuador. The first option consists on a combination of stand-alone home systems for providing energy in the community. The second option proposes the implementation of a centralized system with a distribution network to provide electrical supply in the community. The DN can be composed of a public lighting system, therefore the design of an additional HS that satisfies the total energy consumption in the community must be determined. The selection criterion is the NPC obtained through simulations of various renewable systems that combine PV arrays, Wind turbines and batteries in the Homer Energy software. The selected technoeconomic design guarantees full coverage of the load as well as a secure operation of the system.

This paper is organized as follows. Section II presents data collection in the community Yuwints. Section IIIdescribes the design procedure of the renewable systems for each electrical supply option. Section IV presents simulation results of the proposed systems. Section V presents the conclusions.

\section{Data Collection}

The features of the location as well as its renewable potential were obtained by visiting the Yuwints community, which is located in the Macuma parish at the geographic coordinates $\left(2^{\circ} 09^{\prime} 53,9^{\prime \prime} \mathrm{S}^{\circ} \mid 77^{\circ}\right.$ 34 ' 38,4" W), at an altitude of approximately 492 meters above sea level.

\section{A. Solar Energy Resource}

The Yuwints community is located close to the equator, therefore it receives an abundant supply of solar radiation throughout the year. The monthly average radiation data was obtained from the solar atlas of Equator. According to this information this area receives annual average solar radiation of $4,43 \mathrm{kWh} / \mathrm{m} 2 /$ day. Table 1 shows the monthly average of solar radiation, and the wind speed data for this area.

Table1. Monthly average of solar radiation and wind speed

\begin{tabular}{|c|c|c|}
\hline Month & $\begin{array}{c}\text { Average global radiation } \\
\left(\mathrm{kWh} / \mathrm{m}^{2} / \text { day }\right)\end{array}$ & $\begin{array}{c}\text { Wind speed at 10m } \\
(\mathrm{m} / \mathrm{s})\end{array}$ \\
\hline January & 4,22 & 1,96 \\
\hline February & 4,27 & 1,96 \\
\hline March & 4,42 & 2,29 \\
\hline April & 4,41 & 2,29 \\
\hline May & 4,26 & 2,29 \\
\hline June & 3,92 & 2,48 \\
\hline July & 4 & 2,94 \\
\hline August & 4,35 & 2,55 \\
\hline September & 4,91 & 2,94 \\
\hline October & 4,92 & 2,74 \\
\hline November & 4,99 & 2,68 \\
\hline December & 4,54 & 2,61 \\
\hline Average & 4,43 & 2,48 \\
\hline
\end{tabular}

\section{B. Wind Energy Resource}

According to data provided from wind atlas of Equator, the availability of this renewable resource is not enough to be considered as a feasible electric generation system for this area. However, the monthly average of wind speed will be considered for simulation purposes of possible systems candidates. The annual average wind speed of this region is $2,48 \mathrm{~m} / \mathrm{s}$. Table 1 shows the monthly average wind speed for the Yuwints community.

\section{Hydro Energy Resource}

The nearest water source is a river located $200 \mathrm{~m}$ from the community. There is the availability of a fall of approximately $15-20 \mathrm{~m}$ in a distance of $1,3 \mathrm{~km}$. The Cuzutka river may represent a feasible solution for small scale electricity generation, since the river flow does not decrease significantly throughout the year. 


\section{Biomass Energy Resource}

Biomass could represent another feasible solution for energy generation in this community. Nevertheless, there is neither any study about the amount of raw material available in the community nor a methodology for the correct use of this resource. It should be noted that few years ago a system of domestic biodigesters for food cooking was implemented in some dwellings in the community, but due to lack of maintenance it got damaged, forcing to people to cook by using firewood. Therefore, improving the electricity service to this community will also improve the quality of life of the inhabitants.

\section{E. Load profile of the community}

The community is composed of 34 dwellings, one school and a health center. However the users behavior did not allow a proper record of the consumption data. For instance, users keep the inverter off for long time intervals, while turning on the inverter for a specific use of any appliance for a limited amount of time. The data and information needed to determine the load curve of the users were based on a survey, which aims to determine the electrical appliances available within the dwellings as well as their time and period of use. Table 2 shows the power of typical electrical appliances available in the homes of Yuwints.

Table2. Electrical equipment in the dwellings of Yuwints community

\begin{tabular}{|c|c|c|c|}
\hline \multicolumn{4}{|c|}{ Typical electrical devices in the community } \\
\hline Item & Description & Power $(\mathbf{W})$ & Type of load \\
\hline 1 & Lamp & 11 & DC \\
\hline 2 & Radio & $06-10$ & AC \\
\hline 3 & Television & $65-85$ & AC \\
\hline 4 & DVD & $15-20$ & AC \\
\hline 5 & Computer & $65-150$ & AC \\
\hline 6 & Cell phone chargers & 5 & AC \\
\hline 7 & Satellite phone & 10 & AC \\
\hline
\end{tabular}

Fig.1 shows the representative daily load curve for the whole community.

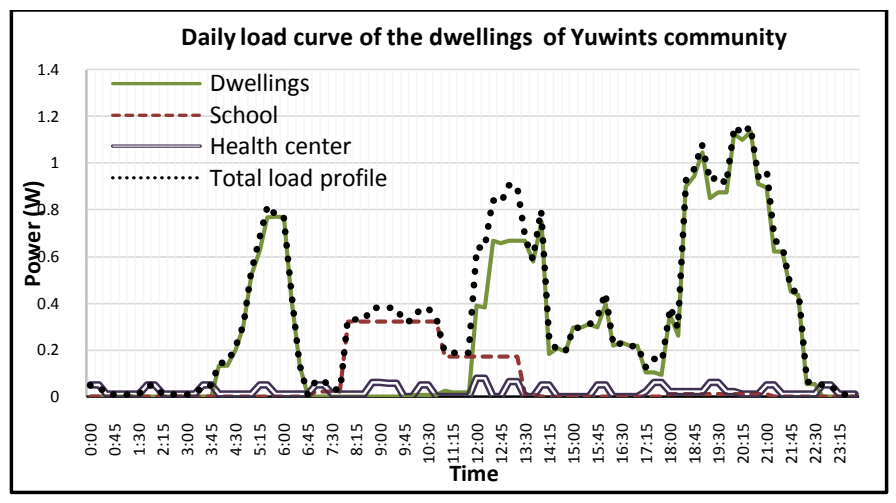

Fig1. Representative daily load curve for Yuwints community

The load consumption of the community presents three specific periods of consumption: morning, afternoon and night (see Fig.1). While the maximum power is $1,157 \mathrm{~kW}$ reached at 20:00, and the daily energy consumed is $8,725 \mathrm{kWh}$. The maximum energy consumption of a dwelling is 0,4935 $\mathrm{kWh} /$ day, the minimum is $0,02475 \mathrm{kWh} /$ day, and the average consumption of the dwellings in the community is $0,196 \mathrm{kWh} /$ day.

\section{SYSTEM DESIGN}

To satisfy the energy requirements of the Yuwints community, it has been considered the analysis of two scenarios:

1) Electrical supply through stand-alone home PV-Wind-battery systems for each dwelling, the health center and the school

2) Electrical supply through a centralized PV-Wind-battery system for the entire community 


\section{A. Stand-Alone Home Systems}

This electrical supply option is the most used in isolated communities of the Ecuadorian Amazon. The usual procedure for supplying electricity involves determining a single load profile that satisfies the energy requirements of each dwelling, and to size the hybrid system based on this load profile. By using this procedure, dwellings with low energy consumption will be oversized.

About sixty percent $(60,8 \%)$ of the dwellings in the community have a lower than average energy consumption. Therefore, it is convenient to classify the dwellings according to their energy consumption and to determine a hybrid system for each category, which are:

- A system for the dwellings with higher than average energy consumption in the community. Using the load profile of the dwelling with highest consumption

- A system for the dwellings with lower than average energy consumption in the community. Using the load profile of the dwelling with average energy consumption

Fig. 2 shows the load profiles for the sizing of both systems. In order to carry out a proper sizing and estimate an accurate cost of the individual system, a dwelling composed of the following components is taken as reference: $2 \mathrm{~m}$ wooden pole to support the PV panel, $8 \mathrm{~m}$ of cable for electrical connection of the PV panel and the electrical panel, an electrical panel, PV components and electrical protections.

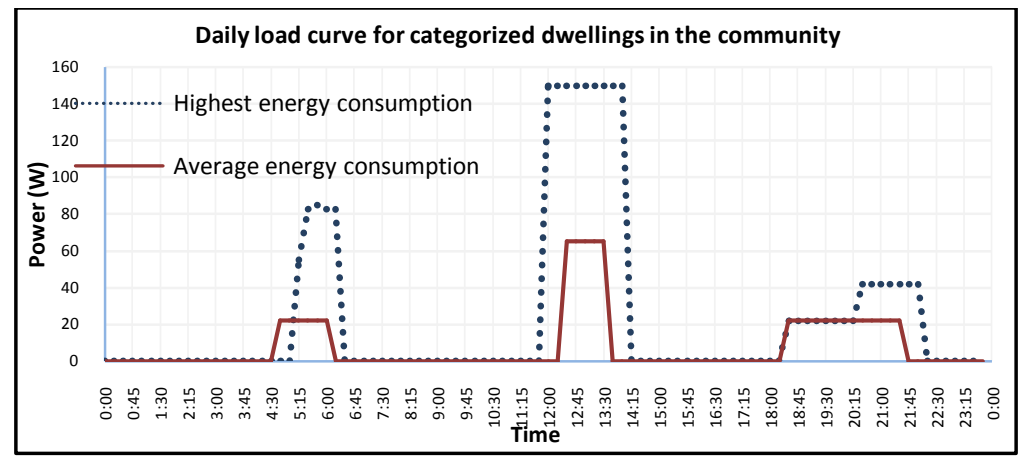

Fig2. Dwellings load profiles classified according to energy consumption

\section{B. Centralized System}

Electrical supply through a centralized system requires a distribution network. To estimate the total cost of this option of electrical supply, the additional cost of the DN must be determined. The first step is to find a suitable location for the PV generation system. The physical characteristics and distribution of dwellings in the community play a key role in the determination of a suitable location for the PV system and the distribution network trajectories. The PV system should be located in a central point of the community, where there is a greater grouping of dwellings. Since, the community is surrounded by dense vegetation, the PV system will be constrained to be located around the landing track (see Fig.3). To find the optimum placement of the PV system, it is proposed an optimization problem.

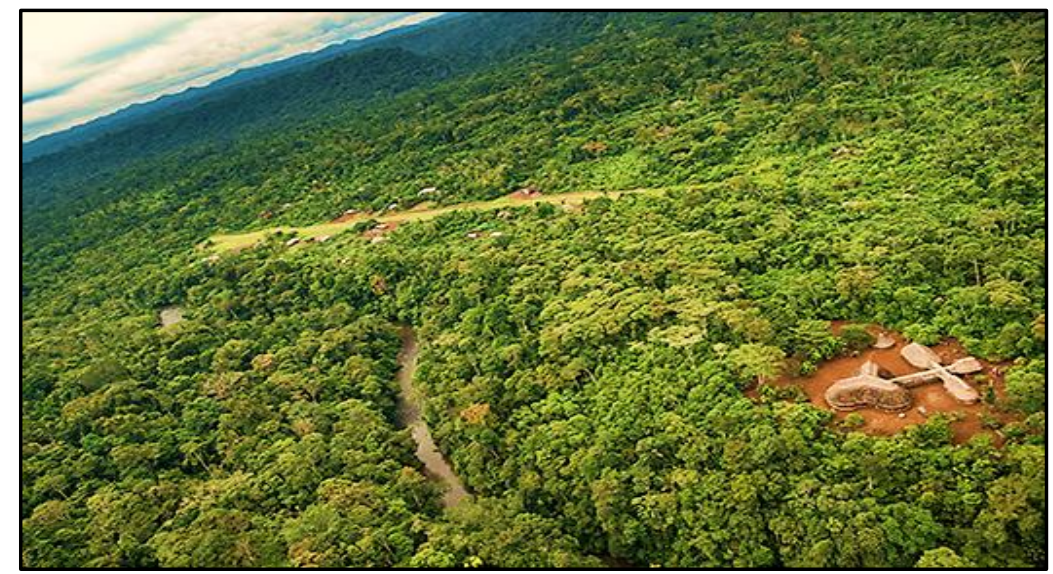

Fig3. Landscape of the community Yuwints 
The procedure to find the formulation of the optimization model is described as follows: As a first step, a system of Cartesian coordinates was established for the community, which has its origin $(0,0)$ in the center of the landing track. The landing track was modeled using the equation of a conic curve. The objective function to be minimized is:

$$
\begin{aligned}
& \min F_{k}(x, y)=\sum_{i=1}^{N}\left[\left(V_{x} i-x\right)^{2}+\left(V_{y} i-y\right)^{2}\right] P_{k i} \\
& k=0,1,2 \\
& \text { s.t } \\
& G(x, y)=218,035 x^{2}+y^{2}-89057
\end{aligned}
$$

Where:

- $\quad$ represents the number of dwellings

- $V_{x} a n d V_{y}$ represent the cartesian coordinates for the dwellings

- $F_{k}(x, y)$ represents the objective function. It is the sum of the distances of each one of the dwellings to the point (x,y), which is constrained to the conic equation $G(x, y)$

- $\quad P_{k}$ represents a weighting vector for the dwellings, where:

- $\quad P_{0 i}=1$

- $\quad P_{1 i}$ is determined according to the distance from the first point determined, $F_{0}$, to each of the dwellings

$P_{1 i}=\frac{1}{\sqrt{\left(V_{x} i-F_{0 x}\right)^{2}+\left(V_{y} i-F_{0 y}\right)^{2}}} \quad i=1 \ldots N$

- $\quad P_{2 i}$ is constituted according to the importance of the electricity supply. The weight value for the dwellings is 1 , for the school is 3 and for the health center is 5

Fig.4 shows the physical distribution of the dwellings in the community, the landing track and the optimum placement point of the centralized PV generation system.

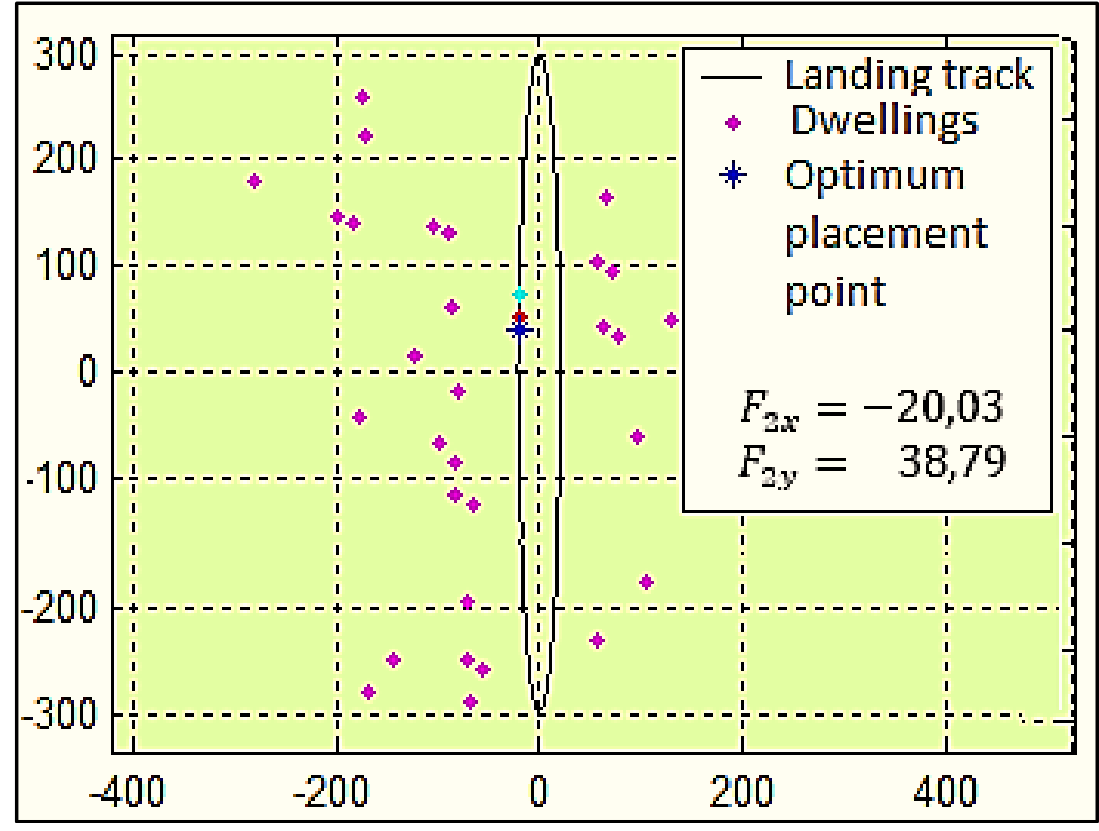

Fig4. Optimum point for location of PV system in Yuwints community

Once the location of the generation system is determined, the second step consists on planning the trajectory of the distribution network, select the appropriate conductor size in each section of the lines and estimate the total implementation cost. Fig.5 shows the design of the DN from the PV system and the trajectory of the distribution lines. 


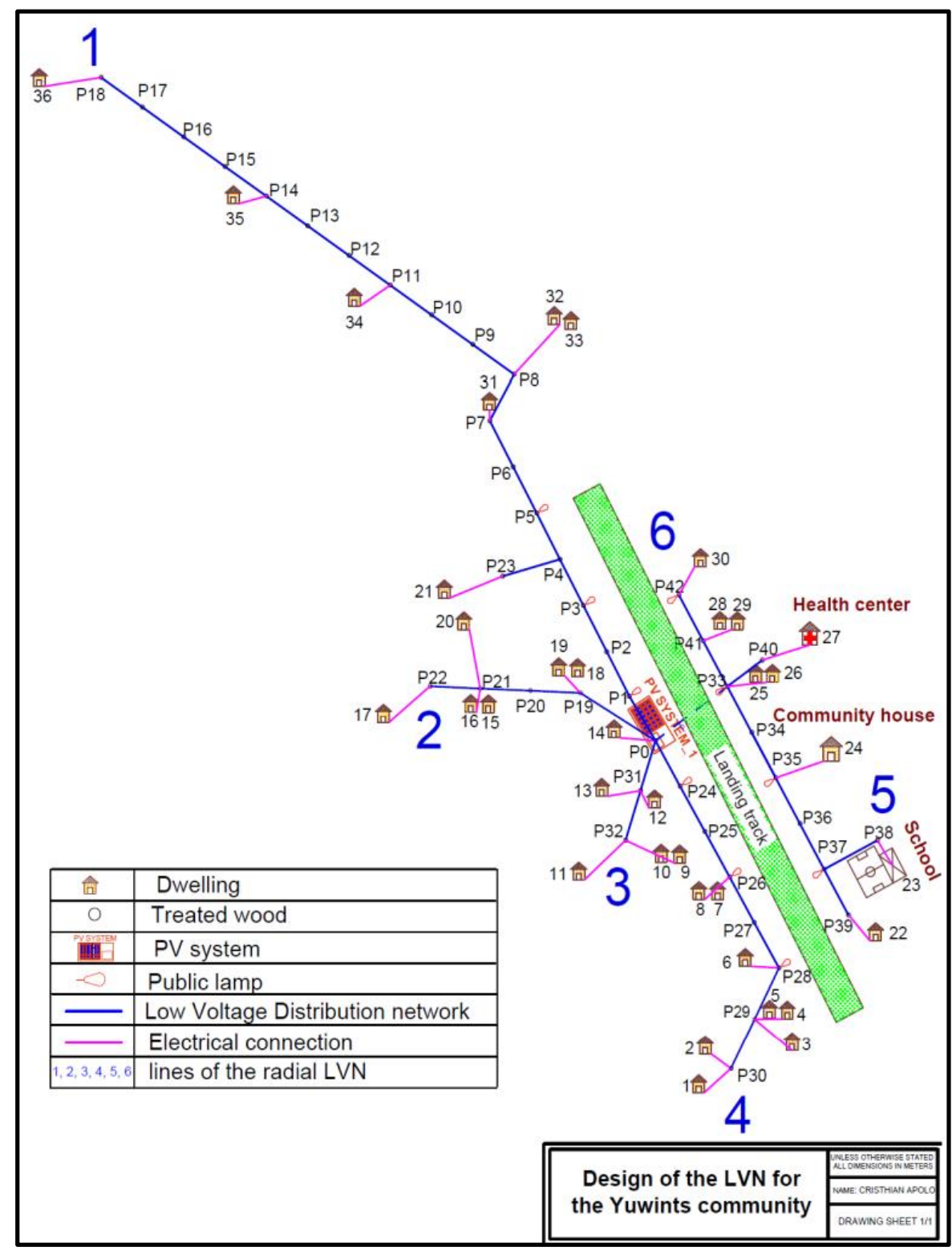

Fig5. Design of the low voltage network for the Yuwints community

The sizing of the electrical conductors for the DN were determined based on guidelines and regulations of two national electricity distribution companies (CENTROSUR, EERSSA).These regulations state the following:

- The sizing of the DN must consider a life cycle of 10 years;

- The maximum limit of voltage drop from the PV generation system to the farthest dwelling should not exceed5\%;

- The minimum conductor size to be used will be 4 AWG and the maximum will be 3/0;

- The Duplex (2x6) electrical conductor will be used for the dwellings connection;

- The size of the neutral conductor will be related according to the gauge of the phase conductor $4(4), 2(4), 1 / 0(4), 2 / 0(2), 3 / 0(2)$.

The DN was planned in a radial form, aerial way and using a $1 \mathrm{~F} 2 \mathrm{C}(220 \mathrm{~V})$ configuration. In order to determine a suitable size of the conductor in each of the sections of the distribution lines, satisfying the voltage limit and minimizing the implementation cost, a MATLAB program was developed. The program performs a linear search of the conductor size for each section, calculates the accumulated voltage drop in the farthest point and if it meets the established limit calculates the total costs. Fig. 6 shows the flowchart of the algorithm for sizing the electrical conductors in a distribution line. 
Techno-Economic Design of a Stand-Alone Photovoltaic System for a Rural Community in the Ecuadorian Amazon

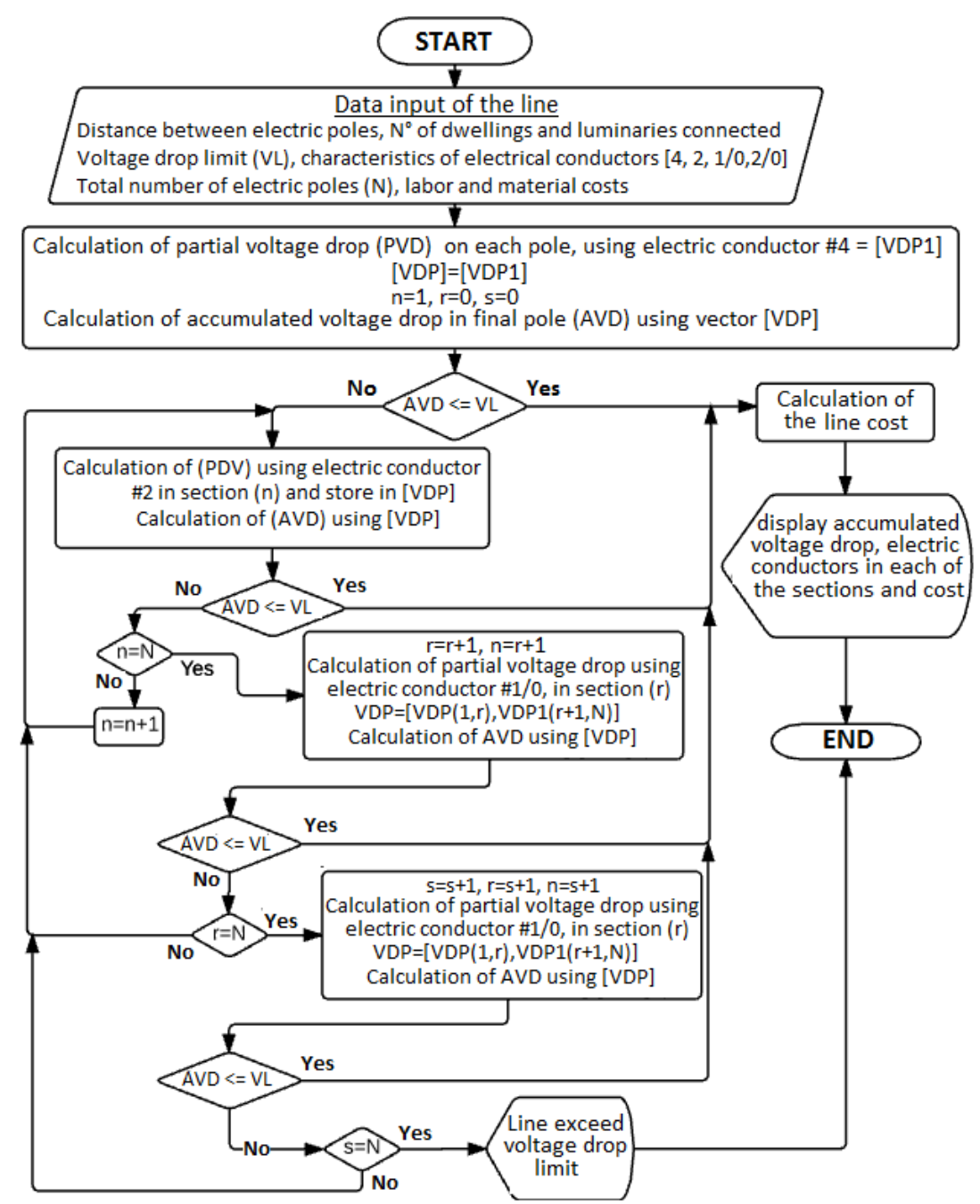

Fig6. Flowchart of the algorithm for sizing the electric conductors in a distribution line

The total cost of each of the lines are calculated considering the material and labor costs. The total cost of the DN considers the cost of the electric poles and the duplex (2x6) conductor for the dwellings connection. Table 3 shows the conductor size; the voltage drop at the most distant point and the implementation cost of each of the lines, as well as the total cost of the DN.

Table3. Size conductor of each of the lines and implementation cost of the DN

\begin{tabular}{|c|c|c|c|c|c|c|c|}
\hline & \multicolumn{2}{|c|}{ Line 1} & Line 2 & Line 3 & Line 4 & Line 5 & Line 6 \\
\hline \multirow{9}{*}{ Section } & $1 / 0$ & 2 & 4 & 4 & 4 & 4 & 4 \\
\hline & $1 / 0$ & 2 & 4 & 4 & 4 & 4 & 4 \\
\hline & $1 / 0$ & 4 & 4 & & 4 & 4 & 4 \\
\hline & $1 / 0$ & 4 & 4 & & 4 & 4 & \\
\hline & $1 / 0$ & 4 & & & 4 & 4 & \\
\hline & $1 / 0$ & 4 & & & 4 & 4 & \\
\hline & $1 / 0$ & 4 & & & 4 & & \\
\hline & 2 & 4 & & & & & \\
\hline & 2 & 4 & & & & & \\
\hline Voltage drop & \multicolumn{2}{|c|}{$4,97 \%$} & $2,26 \%$ & $0,95 \%$ & $4,90 \%$ & $3,17 \%$ & $2,82 \%$ \\
\hline Cost & \multicolumn{2}{|c|}{$\$ 1.613$} & $\$ 343$ & $\$ 146$ & $\$ 512$ & $\$ 497$ & $\$ 278$ \\
\hline Total cost & \multicolumn{7}{|c|}{$\$ 9.415,60$} \\
\hline
\end{tabular}

The proposed DN considers the placement of 10 luminaires for public lighting. Therefore, a new load profile for the community must be determined. The luminaires have an individual power of $80 \mathrm{~W}$, and the period of use is from 18:00 pm to 06:00 am. Figure 7shows the new daily load curve for the Yuwints community. 
Techno-Economic Design of a Stand-Alone Photovoltaic System for a Rural Community in the Ecuadorian Amazon

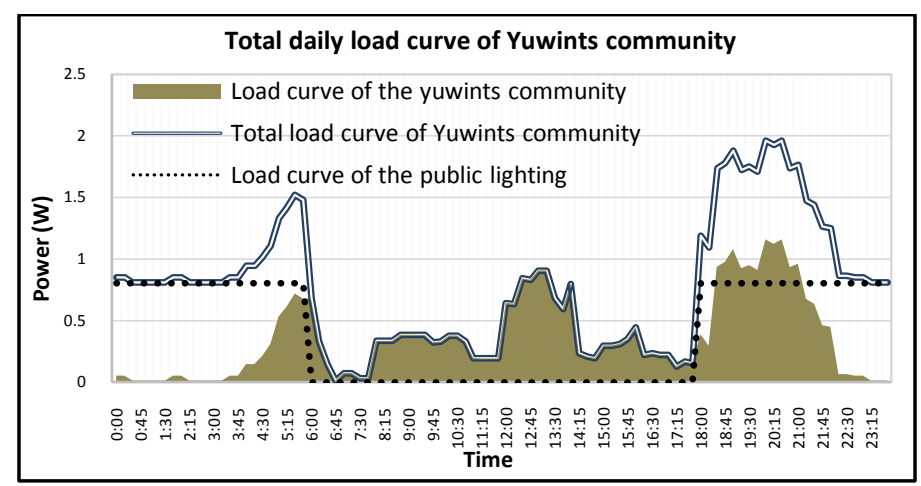

Fig7. Total daily load curve for the Yuwints community

The load profile is modified in such a way that the period with the highest consumption occurs when there is no solar radiation (see Fig.7). The new conductor size configuration of the DN does not change dramatically, and the total cost of the DN is $\$ 9450,60$.

Furthermore, additional consumption due to the losses in the DN must be increased to the total daily load profile of the community. The daily energy losses in the DN were calculated according to [6]. The total daily energy losses calculated are $0,0502 \mathrm{Wh}$. Therefore, they can be neglected.

\section{Simulations}

One of the objectives of this research is to provide energy exclusively from renewable sources. Despite the solar resource is the major renewable source in the area, a PV-Wind-battery scheme is used to determine an optimum system that satisfies the energy requirements at the lowest cost. Fig. 8 shows the schematic diagram in Homer Energy. The scheme consist of a PV system, two types of Wind turbines, a storage system and an inverter.

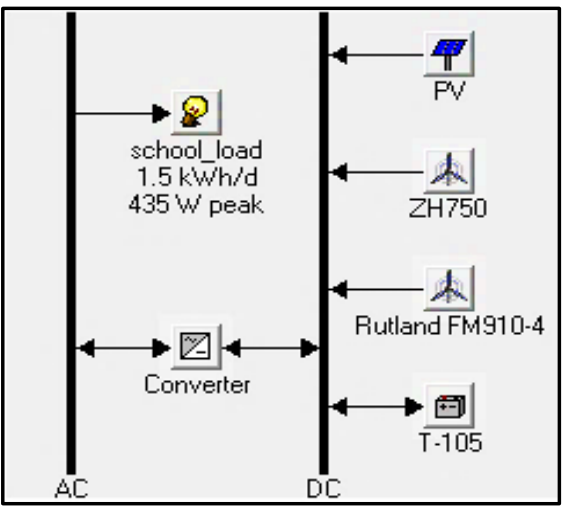

Fig8. Schematic diagram of the renewable system for Yuwints

\section{A. Stand-Alone Home System Modeling}

Table 4 summarizes the sizes and costs of the system components used as inputs to the Homer hybrid model.

Table4. Component cost of the hybrid system

\begin{tabular}{|c|c|c|c|c|}
\hline Component & size & $\begin{array}{c}\text { Capital } \\
\text { cost } \mathbf{( \$ )}\end{array}$ & Replacement cost (\$) & O \& M cost (\$) \\
\hline & $50 \mathrm{~W}$ & 148 & 83 & 10 \\
\hline PV panel & $100 \mathrm{~W}$ & 199 & 134 & 10 \\
\hline \multirow{2}{*}{$\begin{array}{c}\text { Wind turbine } \\
\text { (ZH 750) }\end{array}$} & $300 \mathrm{~W}$ & 502 & 437 & 200 \\
\hline Wind turbine (FM910-4) & $900 \mathrm{~W}$ & 2336 & 1736 & 200 \\
\hline Battery & $180 \mathrm{~W}$ & 2280 & 2200 & 5 \\
\cline { 2 - 5 } & $55 \mathrm{Ah} / 12 \mathrm{~V}$ & 500 & 500 & 5 \\
\cline { 2 - 5 } & $225 \mathrm{Ah} / 6 \mathrm{~V}$ & 200 & 200 & 5 \\
\hline & $180 \mathrm{~W}$ & 366 & 366 & 5 \\
\cline { 2 - 5 } & $350 \mathrm{~W}$ & 271 & 247 & 5 \\
\hline
\end{tabular}

International Journal of Research Studies in Electrical and Electronics Engineering (IJRSEEE) Page | 39 
Techno-Economic Design of a Stand-Alone Photovoltaic System for a Rural Community in the Ecuadorian Amazon

The costs of the charge controller, the electrical connection cable and auxiliary components of the stand-alone home system are included in the cost of the inverter.

The simulations were performed using the three types of batteries presented in Table 4 and different levels of DC voltage for the battery system $(6 \mathrm{~V}, 12 \mathrm{~V}, 24 \mathrm{~V})$. Table 5 summarizes the most economical alternatives for the electrical supply of the dwellings, the school and the health center.

Table5. Simulation results of the stand-alone hybrid system

\begin{tabular}{|c|c|c|c|c|c|c|c|}
\hline $\begin{array}{c}\text { PV } \\
(\mathbf{k W})\end{array}$ & $\begin{array}{l}\mathrm{ZH} \\
\mathbf{7 5 0}\end{array}$ & Batt & $\begin{array}{c}\text { Inv } \\
(\mathbf{k W})\end{array}$ & $\begin{array}{c}\text { Initial } \\
\text { capital }\end{array}$ & $\begin{array}{c}\text { O\&M } \\
(\$ / y r)\end{array}$ & $\begin{array}{l}\text { Total } \\
\text { NPC }\end{array}$ & $\begin{array}{c}\text { COE } \\
(\$ / k W h)\end{array}$ \\
\hline \multicolumn{8}{|c|}{ Dwelling with the highest energy consumption } \\
\hline 0,5 & & 1 & 0,25 & $\$ 1484$ & 93 & $\$ 2670$ & 1,041 \\
\hline 0,5 & 1 & 1 & 0,25 & $\$ 3820$ & 337 & $\$ 8125$ & 3,167 \\
\hline \multicolumn{8}{|c|}{ Dwelling with the average energy consumption } \\
\hline 0,1 & & 1 & 0,1 & $\$ 803$ & 75 & $\$ 1767$ & 2,058 \\
\hline 0,1 & 1 & 1 & 0,1 & $\$ 3139$ & 322 & $\$ 7249$ & 8,444 \\
\hline \multicolumn{8}{|c|}{ Health center } \\
\hline 0,35 & & 2 & 0,1 & $\$ 1551$ & 105 & $\$ 2855$ & 1,035 \\
\hline 0,6 & 1 & 1 & 0,1 & $\$ 3916$ & 345 & $\$ 8324$ & 3,021 \\
\hline \multicolumn{8}{|c|}{ School } \\
\hline 1,1 & & 2 & 0,45 & $\$ 3182$ & 147 & $\$ 5059$ & 0,743 \\
\hline 1,1 & 1 & 2 & 0,45 & $\$ 5518$ & 393 & $\$ 10541$ & 1,548 \\
\hline
\end{tabular}

The total NPC of the electrical supply system for the Yuwints community by implementing the standalone home systems is:

Total $_{N P C}=(21 \times 1767)+(13 \times 2670)+5059+2855=\$ 79731$

\section{B. Centralized System Modelling}

In section III-B, the total cost of the distribution network was determined considering both the load profile of the community without public lighting and the load profile with public lighting. Therefore, a hybrid system for each case is required. The best option will be selected based on the NPC, the technical and social aspects of both systems. The cost of the DN and auxiliary components for electrical connections of dwellings are included in the cost of the inverter. Table 6 shows the inverter cost for the centralized system. The cost of the PV panels, wind turbines and batteries are the same shown in Table 4.

Table6. Inverter cost for the centralized system.

\begin{tabular}{|c|c|c|c|c|}
\hline Power inverter cost & size & capital cost (\$) & Replacement cost (\$) & O \& M cost (\$) \\
\hline System without Public & $2000 \mathrm{~W}$ & 12640,69 & 5824 & 200 \\
\cline { 2 - 5 } lighting & $3000 \mathrm{~W}$ & 13950,25 & 7133,58 & 200 \\
\hline Total system including & $2000 \mathrm{~W}$ & 12675,69 & 5835,69 & 200 \\
\cline { 2 - 5 } Public lighting & $3000 \mathrm{~W}$ & 13985,25 & 7145,25 & 200 \\
\hline
\end{tabular}

The simulations were performed using the three types of batteries presented in Table 4 and different levels of DC voltage for the battery system $(12 \mathrm{~V}, 48 \mathrm{~V}, 96 \mathrm{~V})$. Table 7 summarizes the most economical alternatives for the electrical supply of the community through a centralized system.

Table7. Simulation results of the centralized hybrid system

\begin{tabular}{|c|c|c|c|c|c|c|c|}
\hline $\begin{array}{c}\text { PV } \\
(\mathbf{k W})\end{array}$ & $\begin{array}{c}\text { ZH } \\
\mathbf{7 5 0}\end{array}$ & Batt & $\begin{array}{c}\text { Inv } \\
\mathbf{( k W )}\end{array}$ & $\begin{array}{c}\text { Initial } \\
\text { capital }\end{array}$ & $\begin{array}{c}\text { O\&M } \\
\mathbf{( \$ / y r )}\end{array}$ & $\begin{array}{c}\text { Total } \\
\text { NPC }\end{array}$ & $\begin{array}{c}\text { COE } \\
\mathbf{( \$ / k W h )}\end{array}$ \\
\hline \multicolumn{7}{|c|}{ (a) Yuwints community without public lighting } \\
\hline 6 & & 22 & 2 & $\$ 30201$ & 1232 & $\$ 45944$ & 1,134 \\
\hline 6 & 1 & 22 & 2 & $\$ 32537$ & 1474 & $\$ 51378$ & 1,268 \\
\hline \multicolumn{8}{|c|}{ (b) Yuwints community considering public lighting } \\
\hline 10,5 & 66 & 3 & $\$ 42984$ & 2378 & $\$ 73378$ & 0,86 \\
\hline 10,5 & 1 & 66 & 3 & $\$ 45320$ & 2620 & $\$ 78815$ & 0,924 \\
\hline
\end{tabular}

The NPC of the renewable system for the Yuwints community without consider the public lighting is $\$ 45944$, and the NPC including the public lighting is \$ 73378 .

\section{Analysis of Results}

A PV-battery hybrid system is the most convenient option to supply electricity to the community Yuwints, either by PVHS or by a CPVS. Nevertheless, implementing a CPVS is more economically International Journal of Research Studies in Electrical and Electronics Engineering (IJRSEEE) Page | 40 
attractive than PVHS. The total NPC by implementing PVHS is $\$ 79731$, whereas the total NPC through a centralized system for the same energy requirements is $\$ 45944$. The total NPC of the CPVS considering the public lighting load is $\$ 73378$, which is still lower compared to the NPC of PVHS.

Table 7 shows the simulation results for the centralized system, considering and not considering the energy consumption of the public lighting. The hybrid system shown in Table 7-b requires 4,5 $\mathrm{kW}$ of PV generation and 44 additional batteries than hybrid system in Table 7-a. Therefore, implementing an electrical supply system that considers the public lighting load produces an increase of \$27434 in the NPC of the system shown in Table 7-a.

A lighting system in rural areas provides several advantages such as safety, mobility, recreational activities, etc. However, the need for a lighting system in the whole community or in strategic locations requires further analysis from a social point of view.

\section{Conclusions}

This research presents a comparison between two electrical supply options for a rural community in the Amazon region of Ecuador.

The electrical supply through a centralized system requires a distribution network, which may or may not be integrated by a public lighting system. From the data in Table 7, it is apparent that the more economically option of electric supply is through the centralized system shown in Table 7 -a. The sizing of this system does not consider the additional energy consumption of the public lighting. However, there is the necessity to place public luminaires at strategic points such as: PV generation system, landing track, health center, recreational areas, etc., which justifies the system shown in Table 7-b to be considered as the most suitable option to provide electricity to the community.

\section{ACKNOWLEDGEMENT}

The first author would like to acknowledge the economic and institutional support provided by the cofinanced scholarship program "Senescyt-Polytechnic Institute of Leiria", as well as the support provided by University of Cuenca.

\section{REFERENCES}

[1] N. M. Swarnkar and L. Gidwani, "Analysis of Hybrid Energy Systems for Supply Resdential Electrical Load by HOMER and RETScreen: A Case in Rajasthan, India," 2016.

[2] M. Fatima, "Cost Optimization of a Hybrid Power System for Rural Electrification in India," pp. 1-6, 2016.

[3] S. K. Saraswat and K. V. . Rao, "Comparison of Various Off-Grid Power System Models for a $10 \mathrm{~kW}$ Load at Jaipur in Rajasthan," 2016.

[4] A. Werth, N. Kitamura, I. Matsumoto, and K. Tanaka, "Evaluation of centralized and distributed microgrid topologies and comparison to open energy systems (OES)," 2015 IEEE 15th Int. Conf. Environ. Electr. Eng. EEEIC 2015 - Conf. Proc., pp. 492-497, 2015.

[5] A. Chaurey and T. C. Kandpal, "A techno-economic comparison of rural electrification based on solar home systems and PV microgrids," Energy Policy, vol. 38, no. 6, pp. 3118-3129, 2010.

[6] M. W. Løtveit, Master, and M. Molinas, "System Design and Configuration of a Stand-Alone PV-Biomass Micro Grid," 2014.

Citation: Luis I. Minchala-Avila et al. (2017). Techno-Economic Design of a Stand-Alone Photovoltaic System for a Rural Community in the Ecuadorian Amazon, International Journal of Research Studies in Electrical and Electronics Engineering (IJRSEEE), 3(2), pp.32-41, DOI: http://dx.doi.org/10.204 31/24549436.0302005 .

Copyright: $\odot 2017$ Luis I. Minchala-Avila. This is an open-access article distributed under the terms of the Creative Commons Attribution License, which permits unrestricted use, distribution, and reproduction in any medium, provided the original author and source are credited 